\title{
EARLY PREDICTION OF GRAM-POSITIVE BACTEREMIA IN FEVERISH EGYPTIAN PATIENTS USING SOME SELECTED INFLAMMATORY MEDIATORS
}

\author{
BY \\ Hala A. Farrag ${ }^{1}$, Walid F. Elkhatib ${ }^{2}$, Riham M. Youssef ${ }^{1}$, Mohammad M. Aboulwafa ${ }^{2}$ \\ FROM \\ ${ }^{1}$ National Center for Radiation Research and Technology, Atomic Energy Authority \\ ${ }^{2}$ Department of Microbiology \& Immunology, Faculty of Pharmacy, Ain Shams \\ University
}

\begin{abstract}
Bloodstream infection is an important cause of morbidity and mortality. Some components of the bacterial cell wall bind to receptors on the cell surface of the host monocytes and macrophages and induce cytokines production. This study assessed the levels of IL- 6 and TNF- $\alpha$ in 36 feverish Egyptian patients, with Gram positive bacterial infections. For early prediction of the infection, blood culture samples from feverish patients were collected from different medical hospitals in Cairo, Egypt. The recovered Gram-positive isolates were identified as Staphylococcus species and Micrococcus species. For patients, IL- 6 and TNF- $\alpha$ were measured in the patients' sera by ELISA. Antimicrobial susceptibility was determined for the tested isolates using 16 antibiotics by Kirby Bauer disk diffusion. Cell membrane protein profile was performed to detect the bands responsible for TNF- $\alpha$ production. The IL- 6 and TNF- $\alpha$ in sera of all patients, with Gram-positive bacterial infections, showed significantly $(\mathrm{P}<0.05)$ higher levels as compared to that of their counterparts with negative bacterial blood cultures. Tested isolates showed antimicrobial resistance to most tested antibiotics. The bacterial cell membrane proteins bands between 29-36 kDa were detected in the tested isolates. Some Inflammatory cytokines (IL-6 and TNF- $\alpha$ ) can be used as valuable tools for early prediction of Gram-positive bacterial infections even before culture results are available.
\end{abstract}

Key words: Bacteremia; fever; Il-6; Staphylococci; TNF- $\alpha$.

\section{Introduction}

Interleukin 6 (IL-6) and tumor necrosis factor alpha (TNF- $\alpha$ ) are two cytokines produced by activated macrophages in response to injury. They mediate several systemic changes associated with trauma or infection such as fever, neutrophilia, and increased hepatic acute phase protein synthesis (Lukaszewski et al., 2008). There had been a shift from the predominance of Gram-negative bacteria to predominance of Gram-positive bacteria over the past two decades (Horasan et al., 2011), with an increasing proportion of multi-resistant bacteria and higher recovery of coagulase 
negative staphylococci (CoNS) (Rosa et al., 2014). CoNS are one of the most common infectious agents responsible for nosocomial blood stream infections, especially when patient is on indwelling devices and premature neonates with low birth weight. Therefore, CoNS should not be considered as contaminants as their pathogenic role in nosocomial blood stream infection is continuously proven in different clinical situations (Parashar, 2014). Although Micrococcus is generally thought to be a saprotrophic or commensal organism, it can be an opportunistic pathogen, particularly in hosts with compromised immune systems (Kocur et al., 2006). Micrococcus spp. has been frequently isolated from blood cultures and could represent a cause of infections associated with medical devices (Martin et al., 2008; and Ramos et al., 2009). Peptidoglycan (PepG) and lipoteichoic acid (LTA), two of the major cell wall components in Gram-positive bacteria, have been shown to stimulate the release of some inflammatory mediators (Wang et al., 2000), also the membrane of $S$. aureus $\mathrm{L}$ form was capable to stimulate TNF- $\alpha$ production by macrophages (Kuwano et al., 1997). The increasing worldwide prevalence of antibiotic-resistant staphylococcal strains renders their infections very difficult to treat (Giai et al., 2013). The worldwide mortality associated with $S$. aureus bacteremia ranges from $30 \%$ to $50 \%$ (Kotsaki and Giamarellos-Bourboulis, 2012).

Since the majority of feverish patients are treated empirically with broadspectrum antibiotics as soon as the fever develops, the use of inflammatory markers for early detection of bacterial infections might be essential to reflect the nature of the infection and to guide the choice of more specific antibiotic therapies, even before the culture results are available (Tavares et al., 2005). The present study was established to assess the levels of IL-6 and TNF- $\alpha$ in feverish patients for early diagnosis of Grampositive bacterial infections and for prevention of complications associated with such infections.

\section{Materials and Methods}

\section{Blood Sampling}

Thirty six blood samples were collected by authoritative medical staff of the clinical laboratories (Al-Abasia Fever Hospital, Cairo, Egypt) on fever onset from outpatients according to the standard protocols of these medical institutions. This study was approved by local ethics committees. Collected blood samples were subjected to blood cultures and total white blood cells (WBCs) counting immediately after samples collection. Blood samples were also centrifuged and the separated sera were stored at $20^{\circ} \mathrm{C}$ until use for assays of cytokines and CRP level.

\section{Microbial cultures}

Two blood samples $(5 \mathrm{ml}$ each, were collected separately during the same episode of fever from each patient with sterile precaution) were immediately injected into two ready-made purchased blood culture bottles, mixed, and incubated at $37^{\circ} \mathrm{C}$. The bottles showing no turbidity after 14 days of incubation were discarded, while those showing turbidity within the 14 days were subjected to subculture onto nutrient agar. The inoculated plates were incubated at $37^{\circ} \mathrm{C}$ for $24 \mathrm{~h}$ as described previously (Komar, 
2013). Identification of isolates was carried out at National Cancer Institute (Cairo, Egypt) using, automated system for identification to species level, MicroScan Walk Away 96 SI System (Dade Behring, Germany) and API Staph System (Biomerieux, Marcy-L'etoile, France) according to the instructions of the manufacturers.

\section{Biological assays}

\section{Total WBCs}

Total WBCs were determined for plasma samples using Micros 60 counter (Horiba Diagnostics, USA) after blood collection in EDTA-containing tubes (Tavares et al., 2005).

\section{Serum CRP}

CRP was determined using AVITEX ${ }^{\circledR}$ CRP (Omega Diagnostics, Hillfoots, UK) as described previously (Fisher and Nakamura, 1976).

\section{Human IL-6 and TNF- $\alpha$ levels}

Levels of IL- 6 were measured in the sera collected from the patients and stored at $-20^{\circ} \mathrm{C}$, after blood sample centrifugation, as well as healthy volunteers under the same conditions by using an enzyme linked immunosorbent assay kit Human IL-6 ELISA KIT (RayBio Inc, Georgia, USA) (Van Oers, 1993). Levels of TNF- $\alpha$ were also measured using Human TNF- $\alpha$ ELISA Kit (AviBion Co, Vantaa, Finland) (Seriolo et $a l ., 2006)$. Instructions of the manufacturers were strictly followed in both assays.

\section{Antimicrobial susceptibility testing}

Antimicrobial susceptibility testing of all isolates to Levofloxacin (LEV, 5 $\mu \mathrm{g}$ ),

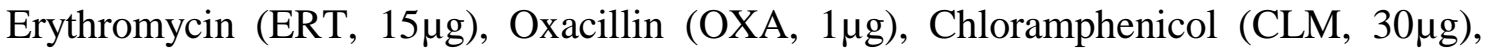

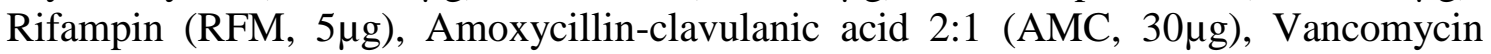

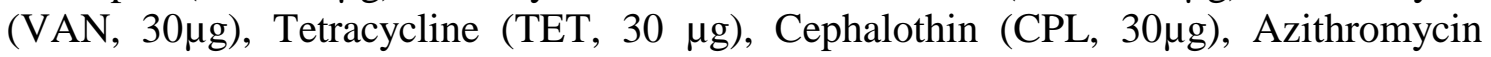

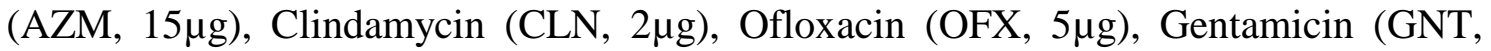

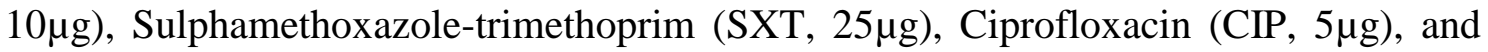
Cefotaxime (CTX, $30 \mu \mathrm{g}$ ) was performed using Kirby Bauer disk diffusion method (Hombach et al., 2013). Antibiotic discs were obtained from Oxoid, LTD (Dublin, Ireland). The results were interpreted according to the guidelines of clinical and laboratory standards institute (CLSI) (CLSI, 2010).

\section{Bacterial cell membrane-protein profiles}

Membrane proteins of the tested isolates were prepared as reported previously (Stewart et al., 2005). Concentration of the membrane proteins were measured as previously described (Upreti et al., 2012). Sodium dodecyl sulphate polyacrylamide gel electrophoresis (SDS-PAGE) of the membrane proteins was performed as mentioned (Moore et al., 2014). Molecular weights of the separated proteins were determined through using standard wide range $(10-250 \mathrm{kDa})$ prestained protein marker 
(Fermentas; Cheshire, UK). Analysis of gel lanes was carried out using AlphaImager ${ }^{\mathrm{TM}}$ 2200 software (San Jose, CA, USA).

\section{Statistical analysis}

Statistical significance of the obtained data for cytokines levels was determined using Student's t-test and P- value $<0.05$ was considered significant. Receiver operating characteristic (ROC) curves, plotting sensitivity versus specificity, to evaluate the diagnostic performance of the tested inflammatory mediators. An area under the curve (AUC) closer to 1 indicates greater diagnostic power (Groeneveld et al., 2001). Sensitivity, specificity, and positive predictive and negative predictive values for the cutoff points that represented the best discrimination, as derived from ROC curves, were also calculated.

\section{RESULTS}

\section{Clinical characteristics}

A total of 36 outpatients (20 males and 16 females with age range 20-55 years) were included, 27 positive cases for microbial infection, nine negative cases. Four healthy laboratory personnel were included in this study. Table (1) shows the number and frequency of positive and negative cases for microbial growth from blood culture samples of the patients. Table (2) shows different bacterial species recovered from the patients.

Table 1. Number and frequency of positive and negative cases for microbial growth from blood culture samples of patients

\begin{tabular}{|c|c|c|}
\hline $\begin{array}{c}\text { Total no. } \\
\text { of }\end{array}$ & $\begin{array}{c}\text { No. of positive blood } \\
\text { cultures-\% }\end{array}$ & $\begin{array}{c}\text { No. of negative blood cultures- } \\
\%\end{array}$ \\
\hline 36 & $27-75 \%$ & $9-25 \%$ \\
\hline
\end{tabular}

Table 2. Identified Gram-positive bacterial species recovered from the patients.

\begin{tabular}{|c|c|c|}
\hline Bacterial isolate & $\begin{array}{c}\text { No. of isolates } \\
(\mathbf{n = 2 7})\end{array}$ & \\
\hline S. aureus & 12 & $44.4 \%$ \\
\hline S. epidermidis & 5 & $18.5 \%$ \\
\hline S. hominis & 1 & $3.7 \%$ \\
\hline S. sciuri & 7 & $26 \%$ \\
\hline S. lugdunensis & 1 & $3.7 \%$ \\
\hline Micrococcus $\boldsymbol{s p p}$. & 1 & $3.7 \%$ \\
\hline Total & \multicolumn{2}{|c|}{$\mathbf{2 7}$} \\
\hline
\end{tabular}

Abbreviations: $S$. = Staphylococcus 


\section{WBCs count, IL-6, TNF- $\alpha$ and CRP of the tested patients}

The total WBCs counts of the patients involved in this study had an average value of $15 \times 10^{3} / \mathrm{mm}^{3}$ for bacteremic patients relative to $9 \times 10^{3} / \mathrm{mm}^{3}$ for non-bacteremic patients and healthy control.

Statistical analysis of the data for IL-6 levels showed P- value of 0.0247 in case of bacteremic relative to non-bacteremic patients. For TNF- $\alpha$ levels P-values were 0.0023 for bacteremic relative to non-bacteremic patients. Average levels of IL-6 and TNF- $\alpha$ in patients with bacteremic and non-bacteremic fever, and healthy control (Fig. 1 $\& 2)$, respectively.

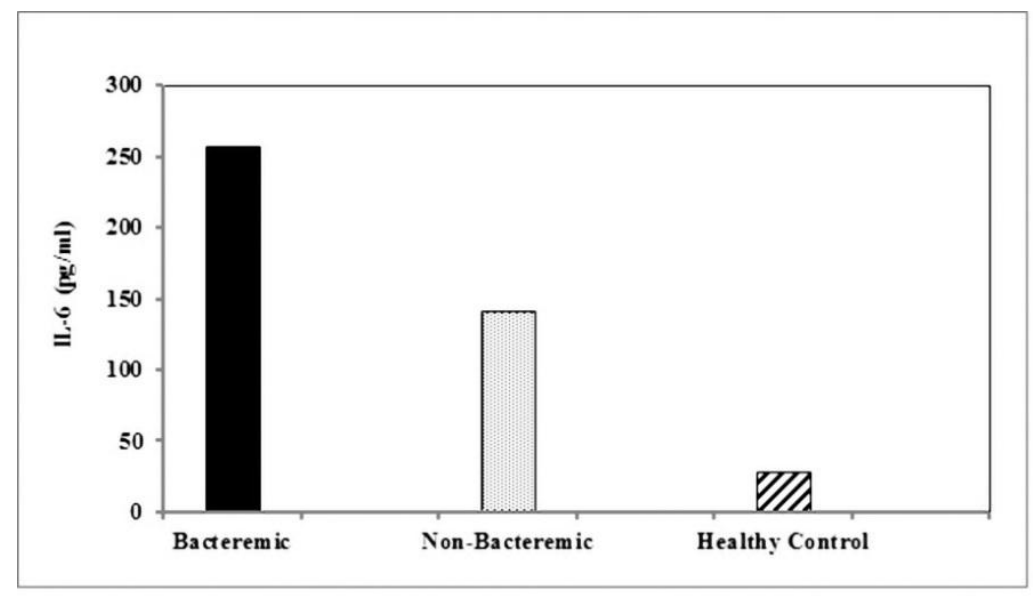

Fig. 1. Average IL-6 levels in patients with bacteremic and non-bacteremic feverish patients as well as healthy control.

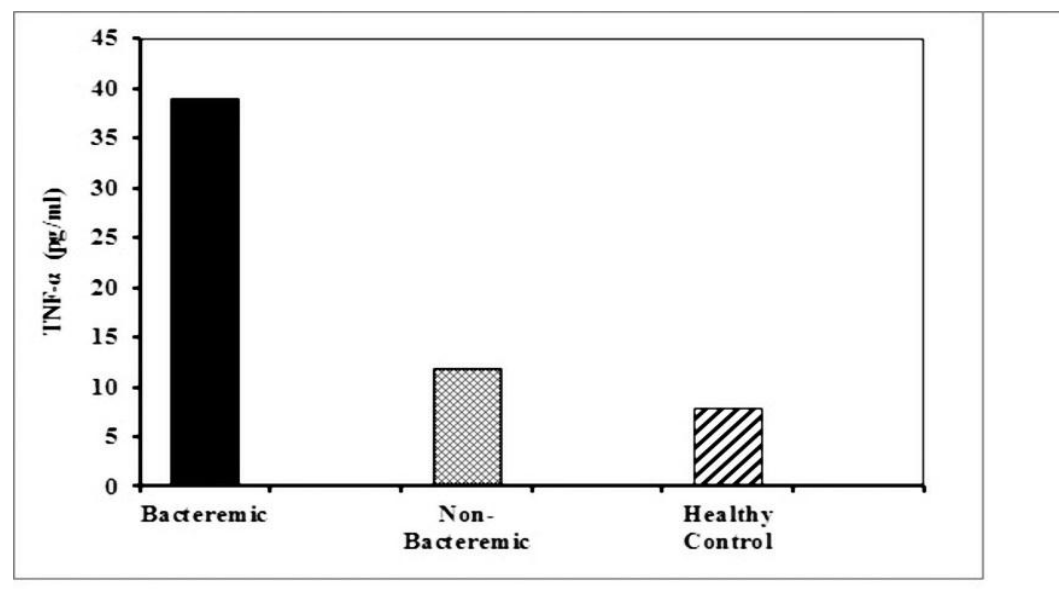

Fig. 2. Average TNF- $\alpha$ levels in patients with bacteremic and non-bacteremic feverish patients as well as healthy control.

The sensitivity, specificity, positive predictive value, and negative predictive value at the best cutoff values of IL-6, and TNF- $\alpha$ based on ROC analysis were 
calculated to be $(77.8 \%, 77.8 \%, 0.77,0.77$, at $157 \mathrm{pg} / \mathrm{ml}$ for IL-6 and $100 \%, 100 \%, 1$, 1 , at $13 \mathrm{pg} / \mathrm{ml}$ for TNF- $\alpha$, respectively). The diagnostic properties of IL-6, and TNF- $\alpha$ levels were compared by calculating the areas under the ROC curves (AUC). The AUC of the ROC curve for IL-6 was 0.78 and that for TNF- $\alpha$ was $1.0(\mathrm{P}<0.05)$ (Fig. 3). This indicates that both IL- 6 and TNF- $\alpha$ would be useful markers for prediction of positive blood cultures in feverish patients.

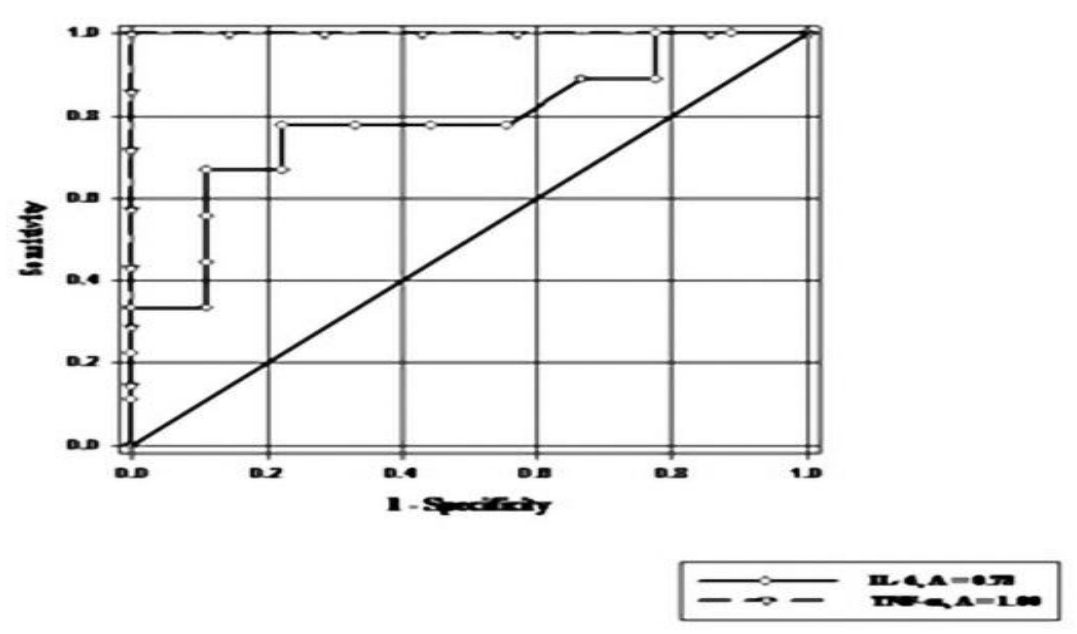

Fig. 3. Receiver operating characteristic (ROC) curves of IL-6 and TNF- $\alpha$ serum levels.

On the other hand, CRP showed strong agglutination in all patients suffering from Gram-positive bacterial infections compared to non-infected patients as well as healthy controls (no agglutination).

\section{Antimicrobial susceptibility}

Antimicrobial susceptibility patterns of the Gram-positive isolates to the tested antibiotics showed high resistance levels to ERT, OXA, CLN, and SXT (67\%) followed by VAN, and AZM (44\%), RFM, AMC, and CPL (33\%). On the other hand, lower levels of resistance $(<22 \%)$ were observed with LEV, CLM, TET, OFX, and CIP. Furthermore, all the tested isolates were sensitive to GNT and CTX (Fig. 4.) 


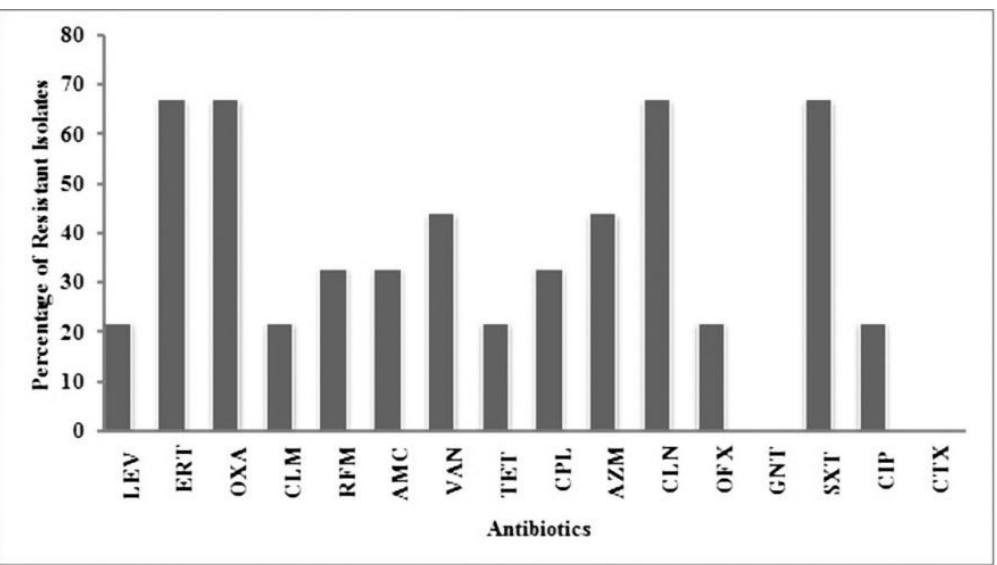

Fig. 4. Resistance of the tested isolates to different antibiotics. Abbreviations: LEV = levofloxacin, ERT = erythromycin, OXA = oxacillin, CLM = chloramphenicol, RFM = rifampin, AMC = amoxycillin-clavulanic acid, VAN = vancomycin, TET = tetracycline, $\mathrm{CPL}=$ cephalothin, $\mathrm{AZM}=$ azithromycin, $\mathrm{CLN}=$ clindamycin, $\mathrm{OFX}$ = ofloxacin, GNT = gentamicin, $\mathrm{SXT}=$ sulphamethoxazole-trimethoprim, $\mathrm{CIP}=$ ciprofloxacin, $\mathrm{CTX}=$ cefotaxime.

Cell membrane protein profiles of the tested bacterial isolates

Cell membrane protein analyses of $S$. aureus and S. sciuri (mostly isolated species from clinical samples) were carried out. Analysis of the lanes of both isolates showed the presence of bands, their molecular weights ranged between 28-36 kDa which are responsible for TNF- $\alpha$ production (Fig. 5).

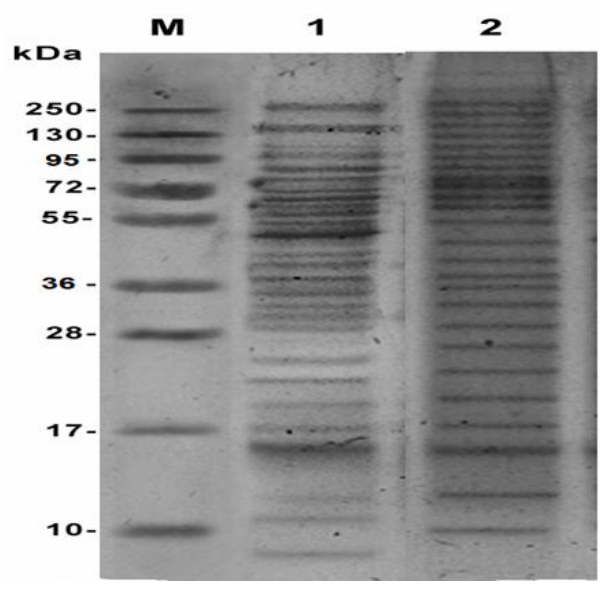

Fig. 5. SDS-PAGE of cell membrane proteins of selected Staphylococcal species. Lanes 1 and 2 represent cell membrane proteins of $S$. aureus and cell membrane proteins of $S$. sciuri, respectively. $M$ is molecular weight of standard protein marker. 


\section{Discussion}

Significant changes in the epidemiology of infections have emerged during the past decade. Gram-positive pathogens have become more predominant. Risk factors such as venous catheters are associated with an increased incidence of Grampositive infections (Rosa et al., 2014).

It has been reported that Gram-positive bacteria induced twice the TNF- $\alpha$ level from human monocytes than Gram-negative bacteria. The principal difference between Gram-positive and Gram-negative bacteria resides in their cell wall structure. Grampositive bacteria have lipoteichoic acid (LTA) instead of lipopolysaccharide (LPS), and also contain more peptidoglycan in their cell wall as compared to Gram-negative bacteria (Hessle et al., 2004). This notion was also supported by a recent study which revealed that stimulation of blood with LPS and LTA for $4 \mathrm{~h}$ led to production of IL-6 and TNF- $\alpha$ in adults and neonates, with higher levels in case of LTA (Koch et al., 2014). Circulating proinflammatory mediators such as IL-6, and CRP have been suggested to be predictive for a systemic microbial bloodstream infection (Tavares et $a l ., 2005)$. The present study demonstrated a significant increase in serum levels of CRP, IL-6 and TNF- $\alpha$ in patients with positive blood cultures than negative cultures patients. Another study demonstrated that CRP was elevated both in septic group, with relation to the control group, and was also found that TNF- $\alpha$ levels were significantly higher in patients with microbiologically-evidenced infections than in patients with only clinically-evidenced infections (El Wakeel et al. 2012).

Escalating bacterial resistance among Gram-positive pathogens means that what were once effective and inexpensive treatments for infections caused by these bacteria are now being seriously questioned. As a whole, multi drug resistant Gram-positive pathogens are rapidly becoming an urgent and sometimes unmanageable clinical problem (Cornaglia, 2009). In the current study, all Gram-positive bacterial isolates, recovered from feverish patienst, showed different resistance levels to the tested antibiotics. Only GNT and CTX represent antibiotics of choice as the tested organisms could not develop resistance against them. Another study also suggested that Cefotaxime showed better susceptibility than other third generation cephalosporin against staphylococci (Jyothsna et al., 2011). The sensitivity pattern of S. aureus to Gentamicin was $92.4 \%$ (Nwankwo and Nasiru, 2011)

It has been reported that cell membrane proteins of $28-36 \mathrm{kDa}$ are responsible for TNF- $\alpha$ induction (Kuwano et al., 1997). In the current study, analyses of cell membrane proteins for $S$. aureus and $S$. sciuri revealed the presence of the bands with molecular weights responsible for TNF- $\alpha$ induction in both strains. Further investigation through using Western blotting and implementation of labeled- and band specific-antibodies, are required to confirm this finding. In conclusion, some inflammatory mediators such as IL-6, TNF- $\alpha$ and CRP would be valuable in early prediction of Gram-positive bacterial infections and this may improve the diagnosis and the therapeutic outcomes, even before culture results are available. Further investigations are required to evaluate the potential association between other cytokines and Gram-positive bacterial infections. 


\section{Acknowledgments}

The authors would like to thank the staff members at radiation unit (NCRRT).

\section{REFERENCES}

CLSI. Clinical Laboratory Standards Institute. M100-S20. Performance Standards for Antimicrobial Disk Susceptibility Tests. 2010 Informal Supplement.

Cornaglia, G. (2009). Fighting infections due to multidrug-resistant Gram-positive pathogens. Clin. Microbiol. Infect., 15, 209-211.

El Wakeel, M.A., El-Kassas, G.M., Fathy, G.A., El Wakkad, A.S.E., Sebaii, H.M.R., El Zayat, S.M.R., and Mohamed, S.I. (2012). Diagnostic and prognostic values of high sensitive C- reactive protein, tumor necrosis factor and interleukin-1 $\beta$ in neonatal sepsis. Aust J Basic Appl Sci 6, 224-228.

Fisher, C. L., and Nakamura, R. (1976). AVITEX-CRP, latex serology test for detection of C-reactive protein. Am. J. Clin. Pathol., 66, 840.

Giai, C., Gonzalez, C., Ledo, C., Garofalo, A., Di Genaro, M. S. et al. (2013). Shedding of tumor necrosis factor receptor 1 induced by protein A decreases tumor necrosis factor alpha availability and inflammation during systemic Staphylococcus aureus infection. Infect. Immun., 81, 4200-4207.

Groeneveld, A. B. J., Bossink, A. W. J., van Mierlo, G. J., and Hack, C. E. (2001). Circulating inflammatory mediators in patients with fever: predicting bloodstream infection. Clin. Diag. Lab. Immunol., 8, 1189-1195.

Hessle, C., Andersson, B., and Wolda, A. (2004). Gram-positive and Gram-negative bacteria elicit different patterns of pro-inflammatory cytokines in human monocytes. Cytokine, 30, 313-318.

Hombach, M., Zbinden, R., and Böttger, E. C. (2013). Standardisation of disk diffusion results for antibiotic susceptibility testing using the sirscan automated zone reader. BMC Microbiol., 13, 225.

Horasan, E.S., Ersoz, G., Tombak ,A., Tiftik, N., and Kaya, A. (2011). Bloodstream infections and mortality-related factors in febrile neutropenic cancer patients. Med. Sci. Monit., 17, CR 304-309.

Jyothsna, K., Madhavi, S., and Rama Rao, M.V. (2011). Antibiotic susceptibility pattern of bacterial pathogens to third generation cephalosporins. Der Pharmacia Sinica, 2 (6), 143-148.

Koch L., Frommhold, D., Buschmann, K., Kuss, N., Poeschl, J. et al. (2014). LPSand LTA-induced expression of IL-6 and TNF- $\square$ in neonatal and adult 
blood: Role of MAPKs and NF- $\square$ B. Mediators of Inflammation; Article ID 283126, http://dx.doi.org/10.1155/2014/283126.

Kocur, M., Kloos, W. E., and Schleifer, K. H. (2006). The Genus Micrococcus. In M. Dworkin, S. Falkow, E. Rosenberg, K. H. Schleifer \& E. Stackebrandt (Eds.), The Prokaryotes 3rd ed New York: Springer, pp. 961-971.

Komar, B. (2013). Evaluation of serum c-reactive protein in diagnosis and prognosis of neonatal septicemia, http://www.webmedcentral.com/article_view/1643.

Kotsaki, A., and Giamarellos-Bourboulis, E. J. (2012). Emerging drugs for the treatment of sepsis. Expert Opin. Emerg. Drugs, 17, 379-391.

Kuwano, K., Ono, S., Akashi, A., Ohishi, M., Shigematsu, H. et al. (1997). Production of a T-cell clone which reacts with membrane proteins of Acholeplasma laidlawii. Microbiol. Immunol., 41, 261-264.

Lukaszewski, R. A., Yates, A. M., Jackson, M. C., Swingler, K., Scherer, J. M. et al. (2008). Presymptomatic Prediction of Sepsis in Intensive Care Unit Patients. Clin. Vaccine Immunol., 15, 1089-1094.

Martin, A., Valdivia-Arenas, M. D., and Namita Sood, M.D. (2008). Micrococcus bloodstream infection in patients with pulmonary hypertension on epoprostenol. Infect. Dis. Clin. Pract., 16, 285-287.

Moore, E. K., Harvey, H. R., Faux, J. F., Goodlett, D. R., and Nunn, B. L. (2014). Electrophoretic Extraction and proteomic characterization of proteins buried in marine sediments. Chromatography, 1, 176-193.

Nwankwo, E.O., and Nasiru, M.S. (2011). Antibiotic sensitivity pattern of Staphylococcus aureus from clinical isolates in a tertiary health institution in Kano, Northwestern Nigeria. Pan African Med J, 8, 4.

Parashar, S. (2014). Coagulase negative staphylococcus: A cause of nosocomial blood stream infection. Int. J. Sci. Res., 3, 277-278.

Ramos, E. R., Hachem. R., Youssef, S., Fang, X., Jiang, Y. et al. (2009). The crucial role of catheters in micrococcal bloodstream infections in cancer patients. Infect. Control Hosp. Epidemiol., 30, 83-85.

Rosa, R. G., Dos Santos, R. P., and Goldani, L. Z. (2014). Mortality related to coagulase-negative staphylococcal bacteremia in febrile neutropenia: A cohort study. Can. J. Infect. Dis. Med. Microbiol., 25, e14-17.

Seriolo, B., Paolino, S., Sulli A., Fasciolo, D., and Cutolo, M. (2006). Effects of antiTNF-alpha treatment on lipid profile in patients with active rheumatoid arthritis. Ann. N Y Acad. Sci., 1069, 414-419. 
Stewart, C. M., Cole, M. B., Legan, J. D., Slade, L., and Schaffner, D. W. (2005). Solute-specific effects of osmotic stress on Staphylococcus aureus. Appl. Microbiol., 98, 193-202.

Tavares, E., Maldonado, R.L., Ojeda, M., and Minano, F.J. (2005). Circulating inflammatory mediators during start of fever in differential diagnosis of Gram-negative and Gram-positive infections in leukopenic rats. Clin. Diag. Lab. Immunol., 12, 1085-1093.

Upreti, G. C., Wang, Y., Finn, A., Sharrock, A., Feisst, N. et al. (2012). An improved Lowry protein assay, insensitive to sample color, offering reagent stability and enhanced sensitivity. BioTechnol., 52,159-166.

Van Oers, M. H. (1993). Interleukin-6, a new target for therapy in multiple myeloma. Ann. Hematol., 66, 219-223.

Wang, J. E., Jorgensen, P. F., Almlof, M., Thiemermann, C., Foster, S. J. et al. (2000). Peptidoglycan and lipoteichoic acid from Staphylococcus aureus induce tumor necrosis factor alpha, interleukin 6 (IL-6), and IL-10 production in both $\mathrm{T}$ cells and monocytes in a human whole blood model. Infect. Immun., 68, 3965-3970.

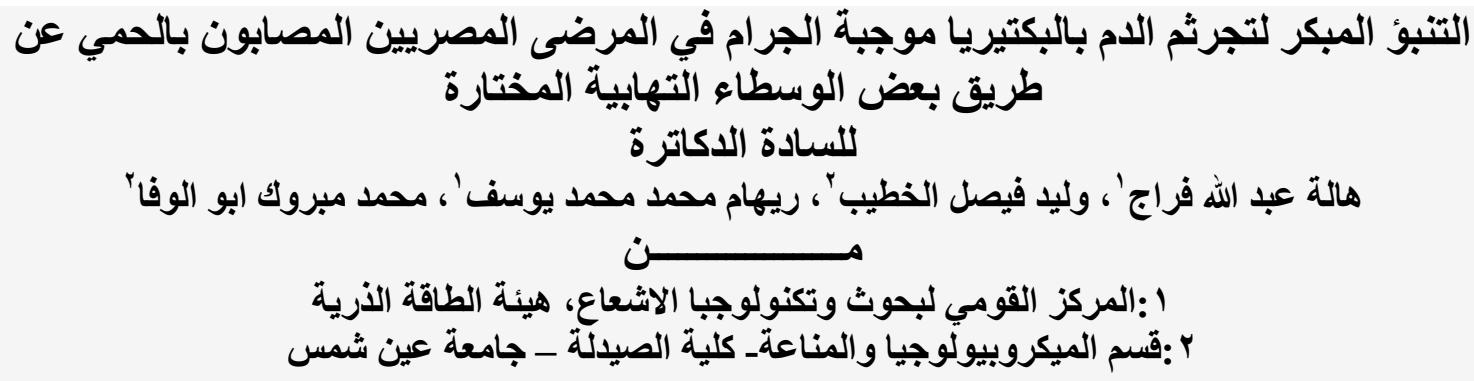

تعد عدوى مجرى الدم هو أحد أهم أسباب المر اضـة و الوفيـات. بعض مكونـات جدار الخليـة البكتيريـة

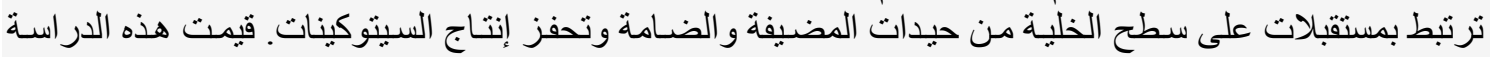

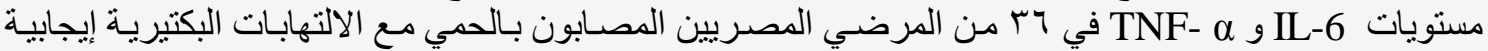

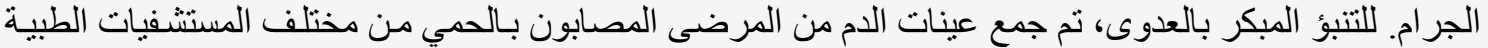

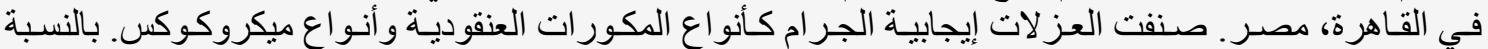

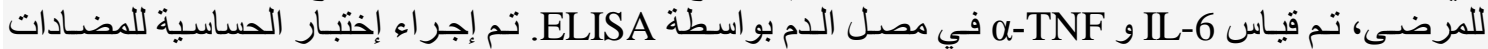

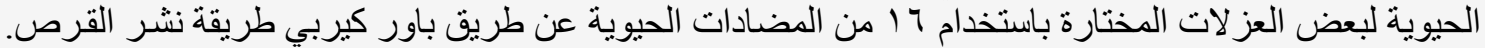

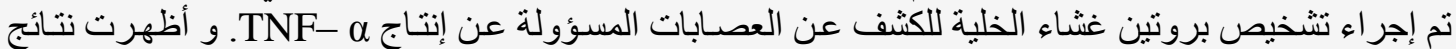

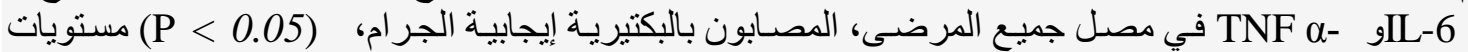

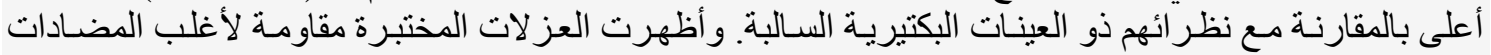

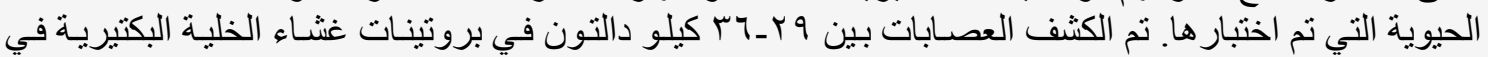

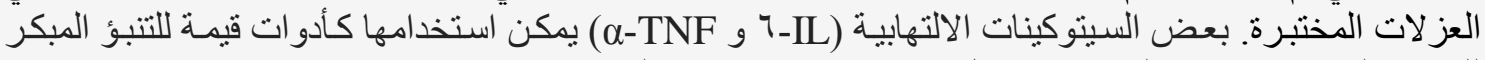
للعدوى البكتيرية إيجابية الجر ام حتى قبل الن تكون نتائج مز الارع الدم متاحة. 